\title{
Instituições de acolhimento e seu potencial educativo
}

\author{
Aline Andrioli \\ Suzane Schmidlin Löhr \\ Universidade Federal do Paraná
}

\section{Resumo}

São apresentados os resultados de dois estudos envolvendo pedagogos e instituições de acolhimento. $\bigcirc$ primeiro, um estudo de caso de uma criança abrigada, conduzido por uma pedagoga, permitiu vislumbrar o conceito de família formulado pela criança. $\bigcirc$ segundo, um estudo de levantamento, visou identificar, em três cidades de diferentes Estados brasileiros, instituições de acolhimento que tinham pedagogos nelas atuando. O levantamento ocorreu entre 2013 e 2014 e constatou que, das 72 instituições identificadas, somente 15 contavam com pedagogos atuantes. Se instituições de acolhimento têm papel educativo, reflete-se sobre o número reduzido de pedagogos por elas contratados.

Palavras chave: Instituição de acolhimento. Educação. Pedagogo.

\section{Host institutions and their educational potential}

\section{Abstract}

This work presents the results of two studies involving educators and host institutions. The first, a case study of a sheltered child, conducted by a pedagogue, allowed to realize the family concept formulated by the child. The second, a survey study, aimed to identify, in three cities, in different Brazilian states, the host institutions which had teachers working in them. The survey took place between 2013 and 2014 and it was verified that among 72 identified institutions, there were only 15 active pedagogues. If the host institutions have educational role, the article reflects in the small number of teachers hired by them.

Keywords: Host institution. Education. Pedagogue. 


\section{Las instituciones de acogida y su potencial educativo}

\section{Resumen}

Se presentan los resultados de dos estudios con los pedagogos y las instituciones de acogida. El primero, un estudio de caso de un niño abrigado, conducido por un pedagogo, permitió de hacer realidad el concepto de familia formulado por el niño. El segundo, un estudio de recopilación de datos, con el objetivo de identificar, en tres ciudades de diferentes estados brasileños, las instituciones de acogida que tenían pedagogos que trabajan en ellas. La encuesta se llevó a cabo entre 2013 y 2014 y encontró que, de las 72 instituciones identificadas, solamente 15 de ellas contaban con pedagogos actuantes con los alumnos. Si las instituciones de acogida tienen función educativa, se refleja sobre el reducido número de profesores contratados por ellas.

Palabras clave: Institución de acogida. Educación. Pedagogo.

\section{Introdução}

Na educação escolar, cada vez mais cobra-se que os profissionais tenham formação específica, adequada e, ainda, que se qualifiquem continuamente. Nos cuidados e na educação formal de crianças pequenas, no Brasil, observam-se intensos movimentos nas últimas décadas para profissionalizar essa área, que recebe destaque com a promulgação da Lei de Diretrizes e Bases da Educação Nacional, em 1996 (BRASIL, 1996), quando a legislação passou a incluir a educação infantil como constituinte da educação básica no país.

Embora pesquisas apontem que, no Brasil, ainda se encontram educadores atuando sem formação específica (SANTOS, 2011; SILVA, 2012), esse quadro sofreu intensas modificações e esses números já estão bem reduzidos. Em 2007, esse contingente representava 6,3\%, de acordo com o Censo Escolar (BRASIL, 2009b, p. 26), e 5,9\% em 2012 . Enquanto em 2007 0,8\% possuíam apenas o ensino fundamental, completo ou incompleto, em 2012, essa porcentagem caiu pela metade. Em 2007, 30,8\% possuíam ensino médio, enquanto, em 2012 esse contingente foi para 16\%. Esses números diminuíram, pois, enquanto em 2007, viam-se 68,4\% docentes da educação básica com ensino superior, em 2012 representavam 78, 1\% (BRASIL, 2013a). 
Em contrapartida, para atuar com crianças e adolescentes em instituição de acolhimento, um espaço marcado, também, por relações de passagem, por coletividades, rotinas um tanto fixas (ROMANELLI, 2013; FEITOSA, 2011), por rupturas e sofrimentos, não é cobrada uma formação específica daqueles que exercem as atividades diretas no cotidiano das crianças. Dos educadores e cuidadores é exigido ensino médio; de seus auxiliares, o ensino fundamental (BRASIL, 2009). Giacomello e Melo (2011) destacam que não se exige nenhuma qualificação dos profissionais que mantêm contato direto com as crianças institucionalizadas, que os subsidie no cuidado com essas crianças, as quais possuem histórias de vida tão peculiares. É importante considerar que, muitas vezes, tais pessoas passam muito mais tempo com as crianças do que os professores.

A formação específica é necessária para profissionais da equipe técnica das instituições, conforme exigências da Norma Operacional Básica de Recursos Humanos do Suas (BRASIL, 2006b) e das Orientações Técnicas para - Serviço de Acolhimento para Crianças e Adolescentes (BRASIL, 2009), mas, sequer, é exigido um pedagogo para constituir essa equipe e contribuir com as reflexões e práticas (des)educativas que ocorrem nesses espaços.

$\bigcirc$ acolhimento institucional é um direito de crianças e adolescentes, mas o que, de fato, circunda esse direito? Aliás, qual direito vem primeiro? $\bigcirc$ de ser criado e educado no seio de uma família, com acesso digno à saúde, moradia, educação e emprego ou o direito à medida protetiva em instituição de acolhimento? Que tipos de aprendizagens a experiência da institucionalização poderá desenvolver? Quais conceitos as crianças e adolescentes estarão construindo de si e do outro, de família e amigos, de privado e coletivo, e de uma série de outros elementos que fazem parte da vida? Quais serão as repercussões a longo prazo, decorrentes de sentimentos, emoções, construções e desmoronamentos experienciados no decorrer da institucionalização? Há muitas perguntas que precisam ser feitas sobre essa medida protetiva assegurada pelo Estatuto da Criança e do adolescente para esses sujeitos ditos de direito. Na tentativa de elucidar algumas, o presente artigo propõe provocações que permitem refletir sobre os conceitos de família, instituição de acolhimento, educação e pedagogia, a partir da legislação, de conceitos teóricos e de achados de duas pesquisas.

A primeira é um estudo de caso do tipo etnográfico (DELGADO; MÜLLER, 2005) e foi desenvolvida em uma instituição da região metropolitana de Porto Alegre - RS. Os dados foram coletados em documentos da instituição 
e por intermédio de entrevistas e observações diretas com o sujeito da pesquisa. Esses últimos procedimentos foram sustentados em estudos que consideram a ludicidade como constituinte das culturas infantis (SARMENTO, 2003; DELGADO, MÜLLER, 2005). Ou seja, como defende Sarmento (2003), Delgado e Müller (2005), traços importantes das culturas infantis foram considerados na estruturação dos procedimentos de coleta de dados adotados, para capturar tanto as vozes quanto as ações da criança. Por isso, fantoches, bonecos, bem como atividades de recorte e colagem, foram utilizados como recursos facilitadores para que a criança pudesse abordar temas complexos de forma aceitável para ela, permitindo ao interlocutor o acesso a seus pensamentos e sentimentos, bem como às suas emoções e vivências.

A segunda pesquisa descreve levantamento, sustentado em Cozby (2003) e Sampieri, Collado e Lucio (2013), visando identificar as instituições que acolhem crianças e adolescentes e aquelas que contam com pedagogos em seu quadro funcional em três cidades de diferentes estados brasileiros (Novo Hamburgo/Rio Grande do Sul, Curitiba/Paraná e Brasília/Distrito Federal).

Ambos os estudos se relacionam ao perceber a instituição de acoIhimento como um espaço social com imenso potencial educativo, que pode 206 ser preocupação da Pedagogia, compreendida com base em teóricos como Libâneo (2010, 201 1), Libâneo e Alves (201 2) e Franco (201 1).

\section{Família e o desenvolvimento humano}

Os seres humanos são mamíferos, biologicamente falando. Segundo Tunes e Tunes (2001) os mamíferos têm menos filhotes que outros animais, sendo que a geração da prole ocorre dentro do ventre materno. Ao nascerem ainda não chegaram ao término de seu desenvolvimento, por isso se faz necessária a amamentação, visto que, geralmente, os recém-nascidos não conseguem digerir e processar a mesma alimentação que os adultos. Por mamarem, os mamíferos vivenciam um contato íntimo e prolongado com a mãe e, de acordo com Tunes e Tunes, esse fato alterou o comportamento dessa espécie ao longo de sua evolução, sendo estes os únicos animais que necessitam de toque, de carícias e de contato físico.

Na verdade, a dependência dos mamíferos jovens em relação aos adultos vai além da alimentação ou do período de amamentação. "Todos os 
mamíferos são sociais, ou seja, vivem e executam as atividades em grupos" (TUNES; TUNES, 2001 , p. 80).

A família é um dos primeiros e o principal contexto de socialização da criança, desde o seu nascimento IAMAZONAS, DAMASCENO, TERTO, SILVA, 2003; POLONIA, DESSEN, 2005; BRASIL, 2006a, fazendo-se presente em inúmeras sociedades. Em 2006, o Conselho Nacional dos Direitos da Criança e do Adolescente, órgão ligado ao Ministério do Desenvolvimento Social e Combate à Fome, publicou o Plano Nacional de Promoção, Proteção e Defesa do Direito de Crianças e Adolescentes à Convivência Familiar e Comunitária. Nesse documento, consta que:

Dada a sua situação de vulnerabilidade e imaturidade, seus primeiros anos de vida [da criança] são marcados pela dependência do ambiente e daqueles que dela cuidam. A relação com seus pais, ou substitutos, é fundamental para sua constituição como sujeito, desenvolvimento afetivo e aquisições próprias a esta faixa etária. A relação afetiva estabelecida com a criança e os cuidados que ela recebe na família e na rede de serviços, sobretudo nos primeiros anos de vida, têm consequências importantes sobre sua condição de saúde e desenvolvimento físico e psicológico (BRASIL, 2006a, p. 27).

A constituição de vínculos afetivos primários, favorecida pela permanência de familiares, nos primeiros anos de vida, associado a condições sociais e culturais favoráveis para a efetivação de seus cuidados, abre possibilidades para a construção de novos vínculos e, posteriormente, auxiliam no desenvolvimento integral e na socialização dos indivíduos (BRASIL, 2006a).

Essa preocupação com os primeiros anos de vida possui estreita relação com o surgimento da infância. Embora desde sempre tenham existido crianças - enquanto seres biológicos de geração jovem -, a infância enquanto categoria social e com seu próprio estatuto é bem recente, surgindo na modernidade. Conforme Sarmento (2003), a construção histórica da infância foi o resultado de um processo complexo de produção de representações sobre as crianças, de estruturação dos seus quotidianos e mundos de vida e, especialmente, de constituição de organizações sociais para as crianças. 
A criança pequena passa a ser o centro das atenções nas famílias,

[... que outrora votara a criança ao estatuto subalterno da companhia das aias e criadas, reconstitui-se através do seu centramento na prestação de cuidados de proteção e estímulo ao desenvolvimento da criança, que se torna, por esse efeito, o núcleo de convergência das relações afetivas no seio familiar, das classes médias e o destinatário dos projetos de mobilidade social ascendente, pelo investimento na formação escolar, por parte das classes populares (SARMENTO, 2003, p. 4).

A institucionalização da escola pública e sua expansão também está associada à construção social da infância, visto que, no século XVIII, foi instituída a libertação do trabalho produtivo para parte da geração mais nova, estendendo-se para toda essa geração com a proclamada escola obrigatória. Para Sarmento (2003), assim a família passou a centrar os cuidados na criança e estimular seu desenvolvimento.

A família nuclear, que virou modelo em grande parte das sociedades industrializadas, divide os papéis de seus integrantes, atribui aos pais a educação dos filhos e isola a família no seu lar (MARTINS; SZYMANSKI, 2004). Para aliar as responsabilidades familiares, sociais e ocupacionais, Machado (2002) afirma que as medidas mais eficazes são as instituições de cuidado e educação, visto que o cuidado de crianças deixou de ser atribuição exclusiva da família, passando a ser política pública e um dispositivo social de destaque no que se refere à promoção do desenvolvimento humano. Nesse sentido, Müller afirma que,

O confinamento da infância na família e na escola é um desdobramento da formação das cidades e da origem da família nuclear. [...] A infância dependeu da delimitação física dos espaços, o que, na atualidade, se manifesta de forma cada vez mais especializada e fragmentada. Surgem os equipamentos e os espaços sociais específicos onde se esperam e se aceitam encontrar as crianças, pois, nos demais, ela é invisível ou um incômodo para os adultos. A modernidade cria a família nuclear - a casa - e a escola como lugares para as crianças (MÜLLER, 2007, p. 170).

Mas as modificações nos entendimentos da criança, da infância, e de suas necessidades, não cessam por aí. Ingberman e Löhr (2007), apontam que, nos últimos 50 anos, intensas modificações sociais, principalmente voltadas à 
educação dos filhos, foram produzidas (e continuam sendo) com a ascensão da mulher no mercado de trabalho.

Associando a escola obrigatória com as novas demandas sociais, que passaram a incluir homens e mulheres no mercado de trabalho, observam-se constantes modificações nos espaços e tempos destinados às crianças. Nas escolas brasileiras, por exemplo, gradativamente, percebe-se a ampliação de dias letivos e do tempo de permanência. Outras instituições passam a ser responsáveis por cuidar das crianças, e não mais apenas a família. No seu cotidiano, a criança amplia a circulação por vários espaços (PARREIRA; JUSTO, 2005). Dessa forma, além de frequentarem as escolas e atividades extracurriculares, é possivel observar-se crianças pobres participando de programas assistenciais ou, ainda, vagando pelas ruas, enquanto as de classe econômica média à alta participam de aulas de línguas estrangeiras, música, danças, dentre outras atividades que evidenciam seu trânsito em diferentes instituições responsáveis por zelar pelos pequenos.

Percebe-se que, em um mundo em constante transformação, o ser humano, para se amoldar, precisa se apresentar flexível e adaptativo, mutável. Hoje a sociedade é outra, a configuração das cidades está diferente de tempos atrás. Antigamente não havia necessidade de casas serem gradeadas, para a segurança de seus moradores, a tecnologia não tinha os mesmos impactos com os quais convivemos e essas são algumas das muitas mudanças na sociedade que tem efeito direto na vida das pessoas. Na mesma direção, a configuração das famílias de hoje não é mais a mesma daquela observada tempos atrás. Mas o que diz a legislação vigente sobre família?

Observa-se que o artigo 226 da Constituição Federal Brasileira, de 1988 (BRASIL, 1988), define por família a união estável entre o casal e a comunidade que for formada por algum dos pais e seus descendentes. Já o artigo 25 do Estatuto da Criança e do Adolescente sustenta a família natural como sendo aquela comunidade formada pelos pais ou por qualquer um deles e seus descendentes. Faz distinção da família extensa ou ampliada, cuja definição está associada à extensão para além do casal ou dos pais e seus filhos, sendo constituída de parentes próximos mantidos por vínculos afetivos e de afinidade.

$\bigcirc$ modelo tradicional de família, composto por pai, mãe e irmãos ainda hoje predomina em nossa sociedade, no entanto, arranjos heterogêneos de famílias são vistos em larga escala (MACHADO, 2002), o que evidencia a necessidade de reconhecer essa diversidade presente no contexto social, 
histórico e cultural, desmistificando a ideia de uma única estrutura familiar considerada como natural (BRASIL, 2006a).

A família é reconhecida enquanto instituição ideal e privilegiada para o desenvolvimento integral de crianças e adolescentes na legislação brasileira vigente (BRASIL, 1988; 1990). Porém, inúmeras famílias encontram dificuldades para proteger e educar seus filhos, sustentando a elaboração de políticas governamentais "[...] paternalistas voltadas para o controle e a contenção social, principalmente para a população mais pobre, com total descaso pela preservação de seus vínculos familiares" (BRASIL, 2006a, p. 16), ao longo de várias décadas. Tais políticas advêm de uma interpretação, por parte do Estado, de que essas famílias são incapazes de cuidar e educar os próprios filhos, sustentando as ações e políticas de perda e suspensão do poder familiar (BRASIL, 2006a). Mas como as famílias brasileiras estão sendo cuidadas?

Há milhares de famílias brasileiras que se encontram às margens da sociedade, longe do acesso às condições básicas para sua existência. Apesar de trabalhos apontarem índices significativos de diminuição da extrema pobreza e da pobreza no Brasil, na última década (BRASIL, 2013), o país ainda enfrenta grandes desigualdades sociais. É importante destacar que "[...] a capacidade 210 da família para desempenhar plenamente suas responsabilidades e funções é fortemente interligada ao seu acesso aos direitos universais de saúde, educação e demais direitos sociais" (BRASIL, 2006, p. 27).

A falta de recursos certamente não é o único aspecto a considerar, pois nem todas as famílias zelam pelas crianças como a legislação preconiza, independentemente de sua condição financeira. Algumas famílias podem não possuir a devida estrutura para dar o suporte que uma criança necessita por seus integrantes apresentarem, por exemplo, incapacidade física ou mental, ocasionadas por alguma doença, acidente, incidente ou mesmo pelo uso de substâncias entorpecentes, por exemplo. Outras podem ser negligentes, apesar de possuírem escolarização completa ou recursos financeiros suficientes. A questão é que, quando, no seio de sua família, crianças e adolescentes tiverem seus direitos violados, uma das medidas protetivas que pode ser aplicada é o acolhimento em instituição. 


\section{O acolhimento institucional}

As instituições de acolhimento possuem subsídio legal no Estatuto da Criança e do Adolescente (BRASIL, 1990), legislação que destaca, a partir da Constituição Federal Brasileira (BRASIL, 1988), a criança e o adolescente como sujeitos de direitos.

Dentre os direitos assegurados no estatuto encontra-se a medida protetiva de acolhimento institucional, que pode ser uma das medidas a ser aplicada quando, por ação ou omissão tanto da sociedade quanto do Estado, ação, omissão ou abuso dos responsáveis, ou mesmo em razão de sua própria conduta, a criança ou adolescente tiverem seus direitos ameaçados ou violados (BRASIL, 1990), ou, ainda, se encontrarem sem referência (BRASIL, 2004). Nessas situações, cabe tanto a conselheiros tutelares quanto ao juizado da infância e da juventude realizar os encaminhamentos para as instituições (BRASIL, 2009a). Estas podem, por sua vez, excepcionalmente e em caráter de urgência, receber crianças e adolescentes sem determinação judicial, devendo comunicar o fato em até 24 horas para que as autoridades procedam com as averiguações e providencias cabíveis.

acolhimento institucional, integra os serviços da Assistência Social, fazendo parte do Serviço de Alta Complexidade do Sistema Único de Assistência Social. Há diferentes modalidades desse acolhimento, incluindo abrigo institucional, casa-lar e residência inclusiva. Além desses, o acolhimento em república, em família acolhedora e a proteção em situações de calamidades públicas e de emergências também constituem os Serviços de Acolhimento de Alta Complexidade (BRASIL, 2009a).

Esses serviços asseguram a proteção integral ao público retirado de seu núcleo familiar, garantindo alimentação, higiene, moradia, dentre outros. No entanto,

[...] o medo e o desamparo estão presentes desde que estas crianças vão para uma instituição. Se vão para uma casa-abrigo é porque alguns de seus direitos básicos à saúde físico-mental não foram respeitados. Na instituição, o temor e a insegurança também estão presentes. A criança não compreende exatamente porque foi parar ali e tenderá a atribuir esse acontecimento a uma vontade ou decisão arbitrárias de alguém. Algumas vezes, a mãe, o pai ou algum outro familiar é responsabilizado pelo seu asilamento numa 
instituição. [...] Outras vezes, a própria criança se responsabiliza pela sua condição, imputando a si, pela via da culpabilização, os motivos de sua transferência para uma casa-abrigo (PARREIRA; JUSTO, 2005, p. 176).

As instituições de acolhimento possuem a orientação de ser semelhantes a residências (BRASIL, 2009), mas a própria legislação reconhece que uma instituição não ocupa o lugar da família, ao assegurar a crianças e adolescentes acolhidos a recolocação em família substituta (BRASIL, 1990). Ainda assim, há crianças e adolescentes que crescem nesses espaços, como evidenciam Silva (2004), Barros e Fiamenghi Jr. (2007), além de Pereira e Costa (2005).

Silva (2004), em Levantamento Nacional de Abrigos, realizado pelo Instituto de Pesquisa Econômica Aplicada (IPEA) em parceria com o Conselho Nacional de Direitos da Criança e do Adolescente, coordenou a pesquisa com 589 abrigos vinculados à Rede de Serviço de Ação, da Secretaria de Assistência Social do Ministério do Desenvolvimento Social e Combate à Fome. Esse levantamento revelou que 52,6\% das 20 mil crianças e adolescentes atendidos viviam há mais de dois anos nas instituições, percentual que, por sua vez, dividiu-se entre dois e dez anos de abrigamento. De lá para cá, outros estu212 dos de menor porte territorial e quantitativo revelaram dados semelhantes sobre o tempo de abrigamento exceder os dois anos preconizados pela legislação (BARROS; FIAMENGHI JR., 2007; PEREIRA, COSTA, 2005).

Ao realizar estado da arte sobre pesquisas envolvendo crianças e adolescentes institucionalizados de 1990 até 2012 , Romanelli (2013) identificou os efeitos da institucionalização na vida dos acolhidos, incluindo sentimentos negativos, problemas psicoemocionais com pares e adultos, atraso no desenvolvimento, aumento de adoecimento, sofrimento e adoecimento psíquico e baixo desempenho escolar.

Como já mencionado, pesquisa realizada revelou 20 mil crianças e adolescentes vivendo nesses espaços (SILVA, 2004). Ou seja, sabe-se que há um grande contingente de crianças que crescem nessas instituições e que a institucionalização traz repercussões na vida do público acolhido. Essas questões indicam a relevância de se pensar nos profissionais que atuam e nos que deveriam atuar no cotidiano dessas crianças e adolescentes, no suporte que recebem ou naquele que deveriam receber, com vistas aos cuidados e à educação condizentes com suas necessidades, seus direitos, deveres, sonhos e desejos. Afinal, a 
instituição de acolhimento é um espaço social que participa do desenvolvimento e da (de)formação de vidas humanas.

Ser abrigado [...] significa lidar com as facetas do abandono e com a falta de referenciais. Significa defrontar-se com a ausência de uma filiação, de um lugar próprio onde o sujeito possa reconhecer-se numa história, no tempo e no espaço, podendo visualizar seu passado, identificar sua linhagem e posicionar-se na rede familiar que assegura seu posicionamento psicossocial primário. Significa deparar-se com a ausência da filiação primária, constituída na vivência afetiva, que designe à criança um lugar psicossocial sólido e seguro, um lugar que the assegure a possibilidade do desejo dentro dos parâmetros da lei, conectando-a assim com os outros e com a cultura de maneira geral (PARREIRA, JUSTO, 2005, p. 176).

\section{Conceito de família sob o olhar de uma criança abrigada}

Para uma criança abrigada, o que é uma família? Quem constitui uma família? Qual é o lugar da família?

Visando conhecer os conceitos de família construídos por uma criança abrigada, conceitos esses elaborados nas vivências de uma menina, o sujeito da pesquisa, em seus quase quatro anos de vida (período esse que inclui o acolhimento institucional e que, até o distanciamento da pesquisadora, estava completando um ano de duração), foi realizado um estudo de caso.

acolhimento da menina, que foi abrigada juntamente com seu irmão menor (com um ano de idade), ocorreu dias após sua irmã de dois anos haver entrado na mesma instituição, em decorrência de uma denúncia. A reunião dos irmãos permitiu vivenciar a alegria do reencontro, conforme relatos da criança, atendendo à promessa que the fora realizada, pelo Conselho Tutelar, de ficar com os irmãos. Na voz da menina: "E daí eu disse assim oh: Não vou!", mas mudou de ideia em seguida, passando a dar seu "sim" para poder ficar com os irmãos.

Meses depois, a irmã de dois anos foi morar com uma tia paterna, após brusco processo de desinstitucionalização, não havendo preparo de nenhuma das crianças para a separação. A menina, sujeito do estudo, alega ter chorado ao perceber que sua irmã não estava mais no quarto dos bebês. Conforme 
relatos de profissionais da instituição, ela se deu conta de que a irmã não estava mais no meio dos outros bebês e, ao questionar sobre onde encontrá-la, ficou sabendo daquilo que the soou como uma triste notícia.

No decorrer das atividades, a garotinha evidencia perceber na mesma tia que acolheu a irmã uma possibilidade de vida após abrigamento, ao dizer que iria, junto a seu irmão, para a casa da titia também. Em outros momentos, declarou a irmã e a tia como mortas, assim como outras pessoas que já estavam distantes de seu convívio, pelas quais evidenciou sentir-se abandonada... "e eu fiquei sozinha" e "eu fiquei enterrada numa terra".

Como Parreira e Justo (2005) defendem, a criança interpretará a sua transferência para uma instituição sob a pressão dos sentimentos aflorados de amor e ódio, movidos pelos vínculos que possui com a família, bem como pelo sofrimento enfrentado. Sendo assim, a interpretação tende a ser voltada à vontade das pessoas que fazem parte de sua história de vida.

Estar no abrigo, para a criança, sem sua mãe, seu irmão, sua tia, sua avó e amiga, sem os aromas e sabores de sua casa, era sinônimo de ficar enterrada em uma terra, nas palavras da garotinha. $O$ que isso significa? A que sentimentos e pensamentos essa fala remete? Certamente, extrapola o olhar de quem vê de fora, de quem não conhece, pois, como afirma Foerster (1996), só somos capazes de ver aquilo que conhecemos.

Como elementos constituintes das concepções da criança sobre família, foram incluídos mãe, pai, irmão, irmã, tia, tio, avós, amiga, educadoras e bicho de estimação, os quais foram trazidos ao longo de toda a pesquisa, ora brincando com bonecos, ora com recorte e colagem, ora verbalizando, relacionados no contexto das vivências particulares da menina, nem sempre simultaneamente, envoltos por seus sentimentos e suas memórias, que nem sempre representam o que, de fato, foi, mas aquilo que ficou registrado na memória afetiva da criança, extrapolando o que pode ser mensurado em palavras.

Analisando essas inclusões, que integram vínculos consanguíneos, animais e pessoas da instituição de acolhimento, observa-se que, ao falar ou brincar de família, a menina integra pessoas com as quais convive ou conviveu, com as quais possui relação de afinidade. Muitas vezes renega algumas dessas pessoas, declarando-as como mortas ou dizendo que agora elas não fazem mais parte. Pesquisa realizada no norte da Inglaterra aponta que as crianças mostram com quem estão relacionadas ao falarem sobre família, bem como as 
companhias com quem estabelecem laços e percebem um sentido de família, utilizando-se de criatividade para explicar suas relações. Ou seja, trata-se de uma noção que é construída nas práticas e não pode ser simplesmente dada por quem está fora (MASON; TIPPER, 2006).

Nas entrevistas lúdicas, a menina declarou o sentimento de abandono, traição e esquecimento por parte da mãe, de quem esperava proteção; da irmã, que foi desinstitucionalizada, e da tia, com as quais possuía maior contato. Em seu discurso, o irmão, também abrigado, tornou-se o seu maior aliado.

Momentos de alegria, na companhia de familiares, também foram relembrados. A menina evidenciou, em suas falas e ações, nas diversas atividades, que família envolve aconchego, proteção, zelo, cuidados, indo ao encontro das alegações de Tunes e Tunes (2001), que afirmam que os mamíferos necessitam de carinho, de toque, de contato físico.

Retrata suas vivências ao lado da avó, da mãe, do pai, das educadoras da instituição, embora também apresente distanciamentos entre o que acredita que deve ser família e a família que vivia. Avó, que ora dá palmada, ora dá carinho; mãe, que ora protege do bicho papão, ora a deixa sozinha. Educadoras que ora trocam a fralda de sua irmã, the dão comida e carinho, ora permitem que ela se vá, sem, sequer dizer adeus.

Ao falar sobre o espaço de uma família, a menina evidencia que a casa é o seu lugar. Ou seja, no desenrolar da investigação, encontrou-se como resultados que a instituição de acolhimento não é o lugar da família, mas sim a casa: - lugar onde se criam vínculos mais estáveis, o lugar onde o sujeito se reconhece como pertencente a uma história, um tempo e um espaço. Por mais que tenha incluído personagens da instituição em seu conceito de família, não vê esse espaço como o lugar da família. Na instituição, a menina viu muitas outras crianças sendo adotadas, voltando para suas famílias, recebendo visitas de parentes, padrinhos afetivos ou futuros pais adotivos. Talvez por conviver com esses fatos e por já ter morado em outros espaços, bem como por compartilhar com outras tantas crianças, ao longo da institucionalização, que já durava quase um ano, o mesmo desejo de viver no seio de uma família, a garotinha deixa claro que a instituição de acolhimento não é o seu lar e que irá para a casa da tia ou apenas para a sua casa, um lar que possa chamar de seu. 
Seu desejo de viver em uma casa, no sentido compreendido pela menina (e não numa casa-abrigo), no seio de uma família, ficou evidente. Aliás, esse é um direito seu!

É importante destacar que querer reencontrar os pais ou alguém que a adote representa a principal preocupação da criança, que necessita reestabelecer sua filiação ou estabelecer outra que a coloque em alguma linhagem (PARREIRA; JUSTO, 2005).

Todas as vivências da menina, sujeito da pesquisa, em seus poucos anos de vida, ofereceram contribuições para a elaboração de hipóteses sobre o mundo, conceitos de família e tantos outros que envolvem a vida. É possível tratar a instituição de acolhimento como uma residência, um lar, como almejam os documentos que orientam as instituições (BRASIL, 1990; 2004; 2006a; 2006b; 2009)? Talvez, mas não para a menina, sujeito de pesquisa. Apesar de reconhecer, nos integrantes da instituição, personagens que possam integrar uma família, bem como fontes de cuidado, zelo e carinho, não percebe a instituição de acolhimento como o lugar de uma família.

É inegável que é preciso muito profissionalismo para atender, adequadamente, às demandas desses espaços, para contribuir com o estabelecimento de vínculos mais estáveis, para amenizar as marcas e consequências da institucionalização, ressaltadas pela literatura (ROMANELLI, 2013 ; PARREIRA, JUSTO, 2005), para que, nesse lugar, com imenso potencial educativo, possam ocorrer atendimentos de fato individualizados, como preconiza a Lei e as normativas da área (BRASIL, 1990; 2004; 2009), com atenção às necessidades das crianças e adolescentes que ali transitam e aos processos de ensino e aprendizagem que ocorrem nesse espaço. Afinal, educação ocorre em distintos espaços sociais (família, empresa, escola, instituições de acolhimento, etc.), por ser uma "[...] prática social, materializada numa atuação efetiva na formação e no desenvolvimento de seres humanos, em condições socioculturais e institucionais concretas" (LIBÂNEO; ALVES, 2012 , p. 26).

Logo, é imprescindível dedicar um olhar atento aos profissionais que atuam nas instituições de acolhimento: um terreno fértil para profundas reflexões. Em diferentes trabalhos, observam-se autores com essa preocupação (BAZON, BIASOLI-ALVES, 2000; IZAR, 2011 ; PEREIRA, 2013). 


\section{A instituição de acolhimento e o profissional da pedagogia}

Normativas como a Norma Operacional Básica de Recursos Humanos do Suas - NOB-RH/SUAS - (BRASIL, 2006b) e as Orientações Técnicas para - Serviço de Acolhimento para Crianças e Adolescentes (BRASIL, 2009) apresentam alguns pressupostos para nortear o trabalho desenvolvido nas instituições de acolhimento, bem como evidenciam, juntamente com a Resolução CNAS n ${ }^{\circ}$ 109 (BRASIL, 2009a), a equipe de referência mínima que deve compor o quadro funcional. Essas normativas exigem um coordenador para cada unidade; um educador/cuidador e um auxiliar de educador/cuidador para até dez usuários, por turno (BRASIL, 2006a; 2009); um assistente social e um psicólogo para atender, no máximo, vinte usuários acolhidos em até duas instituições (BRASIL, 2006 b). A quantidade de profissionais deverá ser aumentada quando houver usuários com demandas específicas, como deficiência, pessoas soropositivas, necessidades específicas de saúde ou idade inferior a um ano (BRASIL, 2006a; 2009).

Ressalta-se que o profissional de pedagogia não é obrigatório em tais instituições, de acordo com legislação vigente, embora a Resolução n 17, de 20 de junho de 2011 (BRASIL, 2011 ) ratifique as definições da NOB-RH/ SUAS, reconhecendo que, além do assistente social e do psicólogo, outras categorias profissionais em nível superior, como o pedagogo, poderão integrar as equipes técnicas.

Apesar do fato de o pedagogo não ser exigido em instituições de acolhimento, esse profissional é encontrado atuando em equipes técnicas de instituições.

Para identificar o panorama no que tange à presença de pedagogos atuando em instituições de acolhimento, fez-se o levantamento em três cidades, de diferentes estados brasileiros (Rio Grande do Sul, Paraná e Brasília), de novembro de 2013 a março de 2014 , constatando-se que havia, nas cidades alvo do estudo, 72 instituições de acolhimento que atendiam a crianças e adolescentes. Dentre essas, apenas 15 possuíam pedagogos atuando em suas equipes de referência, conforme Tabela 1. Na maioria das instituições que tinham pedagogos em sua equipe, havia um profissional atuando em cada instituição. Em uma das cidades havia uma única pedagoga atuando em quatro instituições e, em outra, duas pedagogas atuando em um único local. 


\section{Tabela 1}

Quantitativo de instituições e pedagogos identificados

\begin{tabular}{l|c|c|c}
\hline Cidade - Estado & $\begin{array}{c}\text { Quantidade de } \\
\text { instituições de } \\
\text { acolhimento que } \\
\text { atendem crianças e } \\
\text { adolescentes }\end{array}$ & $\begin{array}{c}\text { Instituições que } \\
\text { possuem } \\
\text { pedagogo(s) na } \\
\text { equipe de referência }\end{array}$ & $\begin{array}{c}\text { Quantidade de } \\
\text { pedagogos }\end{array}$ \\
\hline $\begin{array}{l}\text { Novo Hamburgo } \\
\text { - RS }\end{array}$ & 6 & 4 & 1 \\
Curitiba - PR & 47 & 7 & 7 \\
Brasília - DF & 19 & 4 & 6 \\
Total geral & 72 & 15 & 14 \\
\hline
\end{tabular}

Fonte | As autoras (2014)

Traduzindo esses números, como observável no Gráfico 1, tem-se uma pequena proporção de instituições que possuem esse profissional em seu quadro funcional, mas essa porcentagem já é significativa para suscitar importantes questionamentos e reflexões.

\section{Gráfico 1}

Instituições de acolhimento que atendem crianças e adolescentes: Novo Hamburgo, Curitiba e Brasília

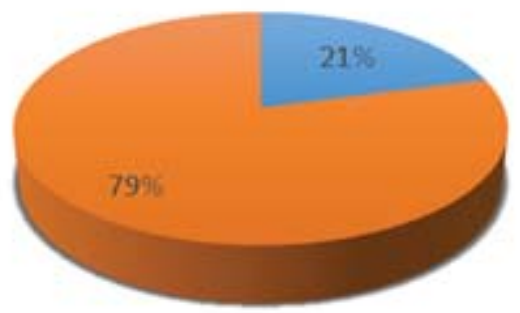

- Com pedagogos $=$ Sem pedagogos

Fonte | As autoras (2014) 
É inegável que a instituição de acolhimento envolve educação e práticas educativas (SANTOS, BASTOS, 2002; NOGUEIRA, COSTA, 2005; MOTTA, FALCONE, CLARK, MANHÃES, 2006; BARROS, FIAMENGHI JR., 2007; PRADA, WILLIAMS, WEBER, 2007; PENNA, CARINHANHA, LEITE, 2009; IZAR, 2011 ; PEREIRA, 2013). Nesse sentido, a pesquisa iniciada será continuada e pretende investigar a atuação de pedagogos em equipes de referência de instituições de acolhimento que atendem a crianças e adolescentes, visando conhecer as atividades que desempenham, analisando, inclusive, as relações com a formação e esse contexto de atuação.

Mas por que o profissional da pedagogia?

Franco (2011) expressa que profissionais da pedagogia, que possuem formação para a compreensão e a transformação da práxis educativa, devem atuar em diversos âmbitos da sociedade que apresentem potencial educativo. Afinal, à Pedagogia cabe, em distintos espaços e momentos, refletir, avaliar e levar à discussão as finalidades e valores relativos à educação (FRANCO, 20111 .

Libâneo (2010; 2011 ) corrobora a ideia de que educação ocorre em muito espaços sociais - e aqui podemos pensar na família, nas instituições de acolhimento, dentre outros -, envolvendo um conjunto de influências do meio social ao desenvolvimento humano. Nesse sentido, o autor distingue as diversas práticas educativas em educação formal, não formal e informal, sendo que o caráter de intencionalidade faz parte das características das duas primeiras (LIBÂNEO, 2010; 2011 ).

A educação intencional é justamente aquela da qual a Pedagogia se ocupa, a qual implica realizar escolhas voltadas aos fins desejáveis, no seu contexto social específico (LIBÂNEO, 2010).

A atuação de pedagogos em equipes de referência de instituições de acolhimento, vistas como um espaço social onde ocorre educação, podem contribuir para atender, adequadamente, às demandas existentes nesse contexto. Vale lembrar que a presença desse profissional nesse espaço social começou pelas demandas da sociedade e não por imposições legais.

Algumas dessas demandas podem ser observadas em documentos que orientam as atividades das instituições, como a NOB-RH/SUAS (BRASIL, 2006a) e as Orientações Técnicas destinadas ao serviço de acolhimento para crianças e adolescentes (BRASIL, 2009). Esses documentos remetem, por exemplo, à 
educação continuada, com vistas à qualificação dos profissionais e ao auxílio no desempenho do papel de educadores/cuidadores (BRASIL, 2006a; 2009); ao acompanhamento de atividades escolares; à elaboração de um projeto político-pedagógico para a instituição lque oriente não apenas o funcionamento interno do serviço, mas também o externo, ou seja, os elos com famílias, comunidade e a rede) e que inclua trabalhar questões pedagógicas e construir estratégias para desenvolver um ambiente estruturante aos acolhidos (BRASIL, 2009). Já que a Pedagogia se preocupa com métodos e maneiras de fazer educação, bem como com a totalidade da problemática educativa e sua historicidade, além de orientar a ação educativa, pode-se inferir que o profissional com essa formação tem muito a contribuir com as instituições de acolhimento.

Pensar nas diferentes práticas (des)educativas que circundam a instituição de acolhimento, envolvendo desde a qualificação do quadro profissional, reflexões e discussões sobre as finalidades e valores relativos à educação que ocorre nesses espaços, até as práticas voltadas às crianças e adolescentes, como o suporte e o acompanhamento da vida acadêmica, à rotina dada ou construída, à construção da individualidade, de regras, do autoconhecimento, dente outras, podem ser atividades enriquecidas com a contribuição do peda220 gogo. Afinal, de acordo com a resolução CNE/CP n 1, de 15 de maio de 2006 (BRASIL, 2006 Art. 4\%), que institui as diretrizes curriculares para o curso de pedagogia, licenciatura, o pedagogo deverá desenvolver atividades como planejar, executar, acompanhar, avaliar e coordenar não apenas tarefas escolares, mas também experiências educativas fora desse contexto; suas atividades envolvem, ainda, a produção e difusão, em contextos escolares e não escolares, de conhecimentos científico-tecnológicos sobre a educação.

Esse profissional também deverá sair do curso apto em dezesseis aspectos, incluindo: participar da gestão das instituições; promover a aprendizagem em espaços não escolares, em diversos níveis e modalidades que envolvam o processo educativo; ajudar a superar os mais diversos tipos de exclusões; desenvolver trabalhos em equipe; participar da elaboração, do acompanhamento e da avaliação do projeto pedagógico; planejar, executar, acompanhar e avaliar programas e projetos voltados à educação nos ambientes escolares ou não escolares; etc. (BRASIL, 2006, Art. 5\%. 


\section{Considerações finais}

A instituição de acolhimento configura um espaço social onde ocorre educação, e os conceitos de família, de relacionamento e tantos outros são edificados.

Ao pesquisar as concepções de família de uma menina acolhida, tornou-se evidente que o principal reconhecimento de família encontrava-se nas pessoas com quem possui parentesco, além de outras companhias, como bichinho de estimação, amiga e pessoas de referência na instituição de acolhimento, mas uma família vive em sua própria casa, e não em uma instituição.

Apesar da família ser defendida como a base da sociedade, há crianças e adolescentes que não podem crescer no seio de sua família, por terem seus direitos básicos violados ou negligenciados. Nesse momento, a sociedade e o Estado assumem o papel que também thes cabe, de afastar criança e adolescentes brasileiros de qualquer forma de negligência, discriminação, exploração, violência, crueldade e opressão, visando assegurar-thes seus direitos de vida, saúde, alimentação, educação, lazer, profissionalização, cultura, dignidade, respeito, liberdade, além da convivência familiar e comunitária (BRASIL, 1988). É nesse contexto que se insere a institucionalização. No entanto, essa mesma sociedade e esse mesmo Estado parecem estar faltando na proteção às famílias e a direitos anteriores de crianças e adolescentes, temática essa que merece estudos mais aprofundados.

A construção do conceito de família, assim como tantas outras situações e outros momentos que envolvem processos de ensino e aprendizagem, fazem parte do cotidiano das instituições. Logo, cabe, também, à Pedagogia e a seus profissionais um olhar atento e preocupado com a educação que circunda esses espaços. Educação se faz em toda a sociedade, em diferentes espaços, e,

[...] à medida em que esta sociedade se tornou tão complexa, há que se expandir a intencionalidade educativa para outros contextos, abrangendo diferentes tipos de formação necessários ao exercício pleno da cidadania; portanto as referências e reflexões sobre as diversas formas e meios de ação educativa na sociedade deverão também constar no rol de atribuições de um pedagogo e, mais que isto, referendar seu papel social transformador (FRANCO, 2011, p. 110). 
Apesar de Pedagogo não ser exigido pela legislação de instituições de acolhimento, as demandas existentes nesses espaços parecem apontar em outra direção, pois esse profissional é encontrado atuando em instituições. $\mathrm{Na}$ pesquisa realizada, observa-se que $21 \%$ de instituições nas cidades de Novo Hamburgo, Curitiba e Brasília possuem pedagogos. Cabe investigar as demandas encontradas no cotidiano dessas instituições, as relações com os demais profissionais e áreas de conhecimento, as atividades desenvolvidas por esse profissional, dentre outras importantes questões que podem contribuir até mesmo com futuras revisões da legislação.

É importante questionar e pesquisar com maior profundidade não apenas o papel de pedagogos em instituições de acolhimento, mas também outros profissionais que atuam nesses espaços, problematizando a formação exigida (ou não) e mesmo a visão profissional que se atribuiu (ou se deixa de atribuir) às atividades que ali se desenvolvem.

\section{Referências}

222 AMAZONAS, Maria Cristina Lopes de Almeida; DAMASCENO, Prisciany Ramos; TERTO, Luisa de Marilak de Souza; SILVA, Renata Raimundo da. Arranjos familiares de crianças das camadas populares. Psicologia em Estudo, Maringá, v. 8, p. 1 1-20, dez. 2003. (Número especial).

BARROS, Raquel de amargo; FIAMENGHI JR., Geraldo A. Interações afetivas de crianças abrigadas: um estudo etnográfico. Ciência e Saúde Coletiva, Rio de Janeiro, v. 12, n. 5, p. 1267-1276, set./out. 2007.

BAZON, Maria Rezende; BIASOLl-ALVES, Zélia Maria Mendes. A transformação de monitores em educadores: uma questão de desenvolvimento. Psicologia: Reflexão e Crítica, Porto Alegre, v. 13, n. 1, p. 199-204, jan./abr. 2000.

BRASIL. Constituição da República Federativa do Brasil. Brasilia: Senado Federal, 1988.

BRASIL. Lei $\mathbf{n}^{\circ} \mathbf{8 . 0 6 9}$, de 13 de julho de 1990. Dispõe sobre o Estatuto da Criança e do Adolescente e dá outras providências. Brasília: Senado Federal, 1990.

BRASIL. Lei $\mathbf{n}^{\circ} \mathbf{9 3 9 4}$, de 20 de dezembro de 1996. Estabelece as Diretrizes e Bases da Educação Nacional. Brasília: Senado Federal, 1996. 
BRASIL. Secretaria Nacional de Assistência Social. Política Nacional de Assistência Social. Brasília: Ministério do Desenvolvimento Social e Combate à Fome, 2004.

BRASIL. Conselho Nacional de Educação. Resolução CNE/CP nº 1, de 15 de maio de 2006. Institui as Diretrizes Curriculares Nacionais para o Curso de Graduação em Pedagogia, licenciatura. Brasília: Conselho Nacional de Educação, 2006.

BRASIL. Conselho Nacional dos Direitos da Criança e do Adolescente - CONANDA et al (Coord.). Plano Nacional de Promoção, Proteção e Defesa do Direito de Crianças e Adolescentes à Convivência Familiar e Comunitária. Brasília: Secretaria Especial dos Direitos Humanos/Ministério do Desenvolvimento Social e Combate à Fome, 2006a.

BRASIL. Ministério do desenvolvimento Social e Combate à Fome. Secretaria Nacional de Assistência Social. Sistema Único de Assistência Social - SUAS. Norma Operacional Básica de Recursos Humanos do Sistema Único de Assistência Social: NOB-RH/SUAS. Brasília: Secretaria Nacional de Assistência Social/Ministério do Desenvolvimento Social e Combate à Fome, 2006b.

BRASIL. Conselho Nacional dos Direitos da Criança e do Adolescente e Conselho Nacional de Assistência Social (Coord.). Orientações Técnicas para o Serviço de Acolhimento para Crianças e Adolescentes. Brasília: Conselho Nacional dos Direitos da Criança e do Adolescente/Conselho Nacional de Assistência Social, 2009.

BRASIL. Conselho Nacional de Assistência Social. Resolução CNAS n 109, de 11 de novembro de 2009. Aprova a Tipificação Nacional de Serviços Socioassistenciais. Diário Oficial Diário Oficial [da] República Federativa do Brasil. Poder Executivo, Brasília, 25 nov. 2009a, n. 225, Seção 1, p. 1.

BRASIL. Ministério da Educação. PESTANA, Maria Inês (Coord.). Estudo exploratório sobre - professor brasileiro: com base nos resultados do Censo Escolar da Educação Básica 2007. Brasilia: INEP, 2009b. Disponível em: <http://portal.mec.gov.br/dmdocuments/estudoprofessor.pdf>. Acesso em: 15 jul. 2014.

BRASIL. Conselho Nacional da Assistência Social. Resolução CNAS n 17, de 20 de junho de 2011 . Ratifica a equipe de referência definida pela Norma Operacional Básica de Recursos Humanos do Sistema Único de Assistência Social - NOB-RH/SUAS e reconhece as categorias profissionais de nível superior para atender as especificidades dos serviços socioassistenciais e das funções essenciais de gestão do Sistema Único de Assistência Social - SUAS. Diário Oficial [da] República Federativa do Brasil, Poder Executivo, Brasília, DF, 21 jun. 201 1, n. 118 , Seção 1, p. 79 
BRASIL. Instituto de Pesquisa Econômica Aplicada - IPEA. Duas décadas de desigualdade e pobreza no Brasil medidas pela Pnad/IBGE. Comunicados do IPEA n. 159, Brasília, out. 2013.

BRASIL. Ministério da Educação. Censo Escolar da Educação Básica 2012 - Resumo Técnico. Brasilia: INEP, 2013a. Disponível em: <http://download.inep.gov.br/educacao_basica/ censo_escolar/resumos_tecnicos/resumo_tecnico_censo_educacao_basica_2012.pdf>. Acesso em: 16 jul. 2014.

COZBY, Paul. Métodos de pesquisa em ciência do comportamento. Tradução de Paula Inez Cunha Gomide e Emma Otta. São Paulo: Atlas, 2003.

DELGADO, Ana Cristina Coll; MÜLLER, Fernanda. Em busca de metodologias investigativas com as crianças e suas culturas. Cadernos de Pesquisa, São Paulo, v. 35, n. 125, p. 161 179, maio/ago. 2005.

FEITOSA, Antônio Genivaldo Silva. A infância abrigada: impressões das crianças na casa abrigo. 201 1, 158 f. Dissertação (Mestrado em Educação) - Programa de Pós-Graduação em Educação, Universidade Federal do Rio Grande do Sul, Porto Alegre, 2011.

FOERSTER, Heins Von. Visão e conhecimento: disfunções de segunda ordem. In: SCHNITMAN, 224 Dora Fried (Org.). Novos paradigmas, cultura e subjetividade. Porto Alegre: Artmed, 1996, p. 59-74.

FRANCO, Maria Amélia Santoro. Para um currículo de formação de pedagogos: indicativos. In: PIMENTA, Selma Garrido (Org.). Pedagogia e Pedagogos: caminhos e perspectivas. 3. ed. São Paulo: Cortez, 2011.

GIACOMELLO, Karina. Jorgino; MELO, Luciana de Lione. Do faz de conta à realidade: compreendendo o brincar de crianças institucionalizadas vítimas de violência por meio do brinquedo terapêutico. Ciência e Saúde Coletiva, Rio de Janeiro, v. 16, p. 1571-1580, 2011 . (Suplemento 1).

INGBERMAN, Yara Kuperstein; LÖHR, Suzane Schmidlin. Assertividade nas relações familiares e na educação dos filhos. In. CONTE, Fátima Cristina de Souza; BRANDÃO, Maria Zilah da Silva. Falo ou não falo: expressando sentimentos e comunicando ideias. 2. ed. Londrina: Mecenas, 2007.

IZAR, Juliana Gama. A práxis pedagógica em abrigos. 201 1, 134 f. Dissertação (Mestrado em Educaçãol - Programa de Pós-Graduação em Educação, Universidade de São Paulo, São Paulo, 2011. 
LIBÂNEO, José Carlos. Pedagogia e pedagogos para quêe 12. ed. São Paulo: Cortez, 2010.

Ainda as perguntas: o que é pedagogia, quem é o pedagogo, o que deve ser o curso de pedagogia. In: PIMENTA, Selma Garrido (Org.). Pedagogia e Pedagogos: caminhos e perspectivas. 3. ed. São Paulo: Cortez, 2011.

LIBÂNEO, José Carlos; ALVES, Nilda. Conversas sobre didática e currículos: a que vem este livro. In: LIBÂNEO, José Carlos; ALVES, Nilda (Org.). Temas de Pedagogia: diálogos entre didática e currículo. São Paulo: Cortez, 2012.

MACHADO, Maria Lucia de A. Encontros e desencontros em Educação Infantil. São Paulo: Cortez, 2002.

MARTINS, Edna; SZYMANSKI, Heloisa. Brincando de casinha: significado de família para crianças institucionalizadas. Natal. Estudos de Psicologia, Natal, v. 9, n. 1, p. 177-187, abr. 2004.

MASON, Jennifer; TIPPER, Becky. Children, Kinship and creativity. In: CHILDREN'S KINSHIP SEMINAR. 2006. Manchester. Working Paper. Manchester: University of Manchester/ Morgan Centre for the Study of Relationships and Personal Life, 2006.

MOTTA, Danielle da Cunha; FALCONE, Eliane Mary de Oliveira; CLARK, Cynthia; MANHÃES, Alex Christian. Práticas educativas positivas favorecem o desenvolvimento da empatia em crianças. Psicologia em Estudo, Maringá, v. 11 , n. 3, p. 523-532, set./dez. 2006.

MÜlLER, Fernanda. Retratos da infância na cidade de Porto Alegre. 2007, 218 f. Tese (Doutorado em Educação) - Programa de Pós-Graduação em Educação, Universidade Federal do Rio Grande do Sul, Porto Alegre, 2007.

NOGUEIRA, Paula Cristina; COSTA, Liana Fortunato. Mãe social: profissão? Função materna? Estilos da Clínica, São Paulo, v. 10, n. 19, p. 162-181, jul./dez. 2005.

PARREIRA, Stella Maris Castro Pipinis; JUSTO, José Sterza. A criança abrigada: considerações acerca do sentido da filiação. Psicologia em Estudo, Maringá, v. 10, n. 2, p. 175-180, maio/ago. 2005.

PENNA, Lucia Helena Garcia; CARINHANHA, Joana labrudi; LEITE, Ligia Costa. A prática educativa de profissionais cuidadores em abrigos: enfrentado a violência vivida por mulheres adolescentes. Revista Latino-Americana de Enfermagem, São Paulo, v. 7, n. 6, p. 98 1-987, nov./dez. 2009. 
PEREIRA, Juliana Maria Fernandes; COSTA, Liana Fortunato. Os desafios na garantia do direito à convivência familiar. Revista Brasileira Crescimento e Desenvolvimento Humano, São Paulo, v. 15, n. 1, p. 19-31, abr. 2005.

PEREIRA, Pâmela Rodrigues. A atuação do pedagogo em abrigos do município de Vitória/ ES. 2013, 126f. Dissertação (Mestrado em Educação) - Programa de Pós-Graduação em Educação, Universidade Federal do Espírito Santo, Vitória, 2013.

POLONIA, Ana da Costa; DESSEN, Maria Auxiliadora. Em busca de uma compreensão das relações entre família escola. Psicologia Escolar Educacional, Campinas, v. 9, n. 2, p. 303312 , dez. 2005.

PRADA, Cynthia Granja; WILLIAMS, Lúcia Cavalcanti de Albuquerque; WEBER, Lídia Natália Dobrianskyj. Abrigos para crianças vítimas de violência doméstica: funcionamento relatado pelas crianças e pelos dirigentes. Psicologia: teoria e prática, São Paulo, v. 9, n. 2, p. 14-25, jul./dez. 2007.

ROMANELLI, Berenice Marie Ballande. $\mathbf{O}$ que é feito dos jovens? Dimensões psicossociais e educativas no processo de acolhimento institucional. 2013. 265f. Tese (Doutorado em Educação) - Programa de Pós-Graduação em Educação, Universidade Federal do Paraná, Curitiba, 2013.

SAMPIERI, Roberto Hernández; COLLADO, Carlos Fernández; LUCIO, María del Pilar Baptista. Metodologia de pesquisa. Tradução de Deisy Vaz de Moraes. 5. ed. Porto Alegre: Penso, 2013.

SANTOS, Francisco Kennedy Silva. O trabalho e a mobilização de saberes docentes: limites e possibilidades da racionalidade pedagógica na educação superior. 2011 . $289 f$. Tese (Doutorado em Educação) - Programa de Pós-Graduação em Educação, Universidade Federal do Ceará, Fortaleza, 2011.

SANTOS, Mirela Figueiredo; BASTOS, Ana Cecília de Souza. Padrões de interação entre adolescentes e educadores num espaço institucional: resignificando trajetórias de risco. Psicologia: reflexão e crítica, Porto Alegre, v. 15, n. 1, p. 45-52, jan./abr. 2002.

SARMENTO, Manuel Jacinto. As culturas da infância nas encruzilhadas da $\mathbf{2}^{\mathrm{a}}$ Modernidade. Instituto de Estudos da Criança. Universidade do Minho: Portugal, 2003.

SILVA, Enid Rocha Andrade da (Org.). O direito à convivência familiar e comunitária: OS abrigos para crianças e adolescentes no Brasil. Brasília: IPEA/CONANDA, 2004. 
SILVA, Sadi José Rodrigues. A formação dos professores do campo: um estudo na serra catarinense. 2012. 164f. Dissertação (Mestrado em Educação) - Programa de Pós-Graduação em Educação, Universidade Federal de Santa Catarina, Florianópolis, 2012.

TUNES, Elizabeth; TUNES, Gabriela. $\bigcirc$ adulto, a criança e a brincadeira. Em Aberto, Brasília, v. 18, n. 73, p. 78-88, jul. 2001.

\author{
Mestranda Aline Andrioli \\ Universidade Federal do Paraná | Curitiba \\ Programa de Pós Graduação em Educação \\ Grupo de Pesquisa | Infância, Adolescência, Família e Sociedade \\ E-mail |andrioli.aline@gmail.com \\ Profa. Dra. Suzane Schmidlin Löhr \\ Universidade Federal do Paraná | Curitiba \\ Departamento de Teorias e Fundamentos da Educação \\ Programa de Pós-Graduação em Educação \\ Grupos de Pesquisa | Cognição, aprendizagem e desenvolvimento humano \\ Infância, Adolescência, Família e Sociedade \\ E-mail | lohr@superig.com.br
}

Recebido 4 ago. 2014 Aceito 30 ago. 2014 